\title{
2015 Autumn Conference
}

\section{Chang-Ju Kim}

Autumn Conference of the Korean Society of Exercise Rehabilitation will be held at the Sang Myung University, Seoul, Korea on October 24, 2015. The topic of the autumn Conference is "Application of exercise rehabilitation on the problems of modern society."

There were many difficulties such as acquiring sufficient funding and venue selection, however, it was possible to prepare the Conference due to the assistance of the officers. On behalf of the society, I am sincerely grateful to those companies that offered substantial support for the Conference.

The pre-registers for the Conference exceeded 400 people with 2 invited lectures, 7 topic presentations, 7 research presentations, 2 special lectures for the undergraduate students, and 18 post presentations. The scale of the autumn Conference will comparatively larger than the recent Conferences.

We have invited Dr. Teri Todd from California State University in USA and Dr. Henrik Oster from University of Lubeck in Germany. Dr. Teri Todd will speak about the effects of physical activity on the autism spectrum disorder and Dr. Henrik Oster will speak on the action mechanisms of circadian clock. These presentations will be helpful for the creation of academic knowledge and application of information in the aspect of exercise rehabilitation.

The official journal of Korea Society of Exercise Rehabilitation,
Journal of Exercise Rehabilitation (JER), switched to English since April, 2013. In addition to such change, JER went further global by getting and established a foundation as an international journal by getting listed in PubMed and PubMed Central in October, 2013.

JER applied for the listing into the Scopus in March 2014, and it has been under the official evaluation since April 2015. It takes an extensive period of time to be listed in the Scopus and all the members of the society are anticipating for the positive answer. On behalf of the society and the members, I deeply wish and believe that JER becomes a Scopus-listed journal. I am confident that awaiting and anticipating for the future for the past and present efforts will be fruitful.

There have been many obstacles for the society, however, the current difficulties will be the process for the joy of tomorrow. Our efforts will be the foundation for establishing the identity of the exercise rehabilitation in the near future.

President of the Korean Society of Exercise Rehabilitation Department of Physiology, College of Medicine Kyung Hee University, 26 Kyungheedae-ro, Dongdaemun-gu, Seoul 02447, Korea E-mail: changju@khu.ac.kr

This is an Open Access article distributed under the terms of the Creative Commons Attribution Non-Commercial License (http://creativecommons.org/licenses/by-nc/3.0/) which permits unrestricted non-commercial use, distribution, and reproduction in any medium, provided the original work is properly cited. 